\title{
REVIEW
}

\section{Spasticity outcome measures in spinal cord injury: psychometric properties and clinical utility}

\author{
JTC Hsieh ${ }^{1}$, DL Wolfe ${ }^{1,2}$, WC Miller ${ }^{3,4}$, A Curt ${ }^{3,4}$ and the SCIRE Research Team \\ ${ }^{1}$ Lawson Health Research Institute, Aging Rehabilitation and Geriatric Care, London, Ontario, Canada; ${ }^{2}$ Department of Physical \\ Medicine and Rehabilitation, University of Western Ontario, St Joseph's Health Care London, Parkwood Hospital, London, Ontario, \\ Canada; ${ }^{3}$ The GF Strong Rehabilitation Research Lab and the School of Rehabilitation Sciences, University of British Columbia \\ (UBC), Vancouver, British Columbia, Canada and ${ }^{4}$ Division of Neurology and International Collaboration On Repair Discoveries \\ (ICORD), University of British Columbia, Vancouver, British Columbia, Canada
}

Study design: Comprehensive review and systematic analyses.

Objectives: Assess published psychometric evidence for spinal cord injury ( $\mathrm{SCl}$ ) spasticity outcome measures. Considerations about the influence of spasticity on function have also been identified to understand treatment effects and guide service delivery.

Setting: London, Ontario and Vancouver, British Columbia, Canada.

Method: Review of measures was based on availability of psychometric data, application in clinical settings and evaluated in $\mathrm{SCl}$ patients.

Results: Ashworth and Modified Ashworth Scales (AS, MAS), Penn Spasm Frequency Scale (PSFS), Spinal Cord Assessment Tool for Spasticity (SCATS), Visual Analogue Scale self-rated scale of spasticity (VAS) and the Wartenberg Pendulum Test (WPT) were included in this review. The most frequently used tools for SCI spasticity measurement include the AS, MAS, PSFS and VAS, of which the latter two are self-report spasticity measures. The SCATS has been partially validated for $\mathrm{SCl}$, but is not widely used. The WPT has been minimally validated despite its use in a large-scale SCI spasticity randomized controlled trial.

Conclusions: Since spasticity is multidimensional, focusing on one or two spasticity outcome measures can misrepresent the extent and influence of spasticity on SCl patients. Different scales measure different aspects of spasticity and individual tools correlate weakly with each other. Spasticity may be better measured with an appropriate battery of tests, including the AS or MAS, along with PSFS. These tools would benefit from further reliability and responsiveness testing. Tools that assess the influence of spasticity on patient activities, participation and quality of life are important, but lacking. Spinal Cord (2008) 46, 86-95; doi:10.1038/sj.sc.3102125; published online 2 October 2007

Keywords: spinal cord injury; spasticity; outcome measures; reliability; validity

\section{Introduction}

The frequency of spastic paralysis after spinal cord injury (SCI) has been observed to be $65-78 \%$ of individuals with traumatic SCI. ${ }^{1-4}$ Greater than a quarter (that is, $28-43 \%$ ) identify spasticity as a significant problem ${ }^{1,2,4,5}$ and almost one half (that is, 43-49\%) receive pharmacological treatment for this secondary condition. ${ }^{3,4}$ Although muscle spasms and/or spasticity may be of some benefit in the maintenance of muscle tone, muscle mass and blood circulation, it is commonly cited as one of the most problematic prevalent secondary conditions after SCI. ${ }^{5-7}$ Typically, spasticity can

Correspondence: Dr JTC Hsieh, Department of Physical Medicine and Rehabilitation, St Joseph's Health Care London, Parkwood Hospital, 801 Commissioners Road East, London, Ontario, Canada N6C 5J1.

E-mail: j.hsieh@sympatico.ca

Received 13 August 2007; revised 23 August 2007; accepted 26 August 2007; published online 2 October 2007 interfere with various body functions such as ambulation and hand or upper limb control as well as bowel and bladder function. It can also limit range of motion, cause pain and/or cause additional stress to muscles and joints. ${ }^{1-3,7}$ It has been reported to significantly impact activities of daily living, limiting workplace participation, as well as adding to the cost of medications and attendant care. ${ }^{1,3,7,8}$

Spasticity was originally described as 'a motor disorder, characterized by a velocity-dependent increase in tonic stretch reflexes (muscle tone) with exaggerated tendon jerks, resulting from hyper-excitability of the stretch reflex as one component of the upper motor neurone syndrome'. ${ }^{9}$ Others have proposed new definitions, including: description of spasticity as 'disordered sensori-motor control, resulting from an upper motor neurone lesion, presenting as intermittent or sustained involuntary activation of muscle', ${ }^{10}$ 
or 'characterization of spasticity comprising intrinsic tonic, intrinsic phasic and extrinsic components' ${ }^{11}$ These definitions are more inclusive of clinical signs and symptoms of 'spasticity' and better reflect its multidimensional nature. ${ }^{12-14}$

Other considerations involve understanding the pattern of spasticity and how it affects functional activities, either positive or negative. In addition, changes in patterns of spasticity may indicate hidden and/or developing clinical complications such as urinary tract infections, skin problems (pressure sores) and other medical issues. ${ }^{13}$ The multidimensional and functional aspects of spasticity are best characterized within a suitable framework such as the International Classification of Functioning, Disability and Health (ICF). ${ }^{15}$ The ICF is an international, recognized classification system, which considers measurement and other aspects of health according to domains of body structure and function as well as Activity and Participation restrictions within bodily functions, individual activities and societal interactions. ${ }^{15}$

Finally, it is important, when selecting the best outcome measurement tool, to consider matching the intended purpose of the data with the utility of potential tools. For example, a clinician may be interested in characterizing the nature of the spasticity in a patient to guide treatment decision-making, whereas a researcher may focus on tools that permit the determination of significant differences in a group of patients in response to an intervention. Feinstein et al. ${ }^{16}$ identified six uses for outcome data including determining compensation, predicting prognosis, planning placement, estimating care requirements, assisting with the choice among specific types of care and determining change in health status secondary to intervention.

The present review is focused on assessing the various outcome measures that have been employed clinically to assess SCI-related spasticity within an ICF framework. Specifically, the psychometric properties (that is, reliability, validity, responsiveness) and clinical utility of spasticity outcome measurement tools were evaluated. The primary objective is to provide a guide for clinicians, with a summary and assessment of the available psychometric evidence, in order to assist the selection of the most appropriate tools for the measurement of spasticity. Thorough spasticity assessment requires an evaluation over the entire range of each joint to be tested. Similarly, selection of the optimal tools to measure spasticity requires consideration of the various issues noted above, each involving a range of alternatives. Secondarily, the summary of available evidence should also assist in the identification of outcome measurement tool gaps that need to be developed to measure more comprehensively the multiple aspects of spasticity secondary to SCI.

\section{Methods}

This review targeted clinically applied tools for which there was at minimum one peer-reviewed study that examined psychometric properties (that is, reliability, validity or responsiveness) using an SCI population. Pubmed, CINAHL and EMBASE databases were searched (1986 to January 2007) to locate papers reporting on SCI spasticity outcome measures with psychometric data. Additional articles were identified by hand-searching the references of papers obtained from the electronic search. The key word 'spinal cord injury' and variants were used across each of the databases in combination with the following terms: validity, reliability, inter-rater reliability, intra-rater reliability, test-retest reliability, reproducibility, responsiveness, sensitivity to change, evidence-based medicine, outcome measures, clinical assessment tools, scales and measures.

Psychometric data were extracted from papers reporting findings including reliability, validity and responsiveness in addition to information pertaining to clinical utility such as interpretability, acceptability and feasibility. Following this, specific findings from individual articles were evaluated according to the established criteria put forth by the Health Technology Assessment (HTA) programme ${ }^{17}$ and other sources. ${ }^{18}$ Additional methodological details are available at http://www.icord.org/scire/pdf/SCIRE_CH22.pdf. ${ }^{19}$

\section{Results}

The present review identified 6 out of 66 SCI-related spasticity outcome measurement tools that had been tested psychometrically. ${ }^{19}$ These included the Ashworth and Modified Ashworth Scale (AS and MAS) and Penn Spasm Frequency Scale (PSFS), which are applied frequently in routine clinical SCI settings. ${ }^{20}$ The Visual Analogue Scale (VAS), the Spinal Cord Assessment Tool for Spastic reflexes (SCATS) and the Wartenberg Pendulum Test (WPT) were also included in the analysis as they met the inclusion criteria of having at least one article addressing psychometric properties and having been categorized as clinical tools by various investigators. ${ }^{12,21-23}$ Table 1 outlines the procedural attributes for each tool, including the specific construct being measured, test procedures, scoring methods and the administration time. Further information about the clinical utility for each of these tools is summarized in Table 2 .

\section{Ashworth and Modified Ashworth Scale}

The Ashworth measure of spasticity was developed as a simple clinical classification to assess the antispastic effects of carisoprodol in multiple sclerosis. ${ }^{24}$ It is a five-point nominal scale focusing on the subjective clinical assessment of tone. For the MAS, an additional grade was added $(1+)$ to enhance sensitivity to accommodate hemiplegic patients who graded typically at the lower end of the scale, more specifically to measure elbow flexor spasticity in patients with multiple sclerosis. ${ }^{25}$ These measures have since been adopted for assessing spasticity in a variety of indications including SCI, ${ }^{26}$ although it is important to recognize that there are differences in the characteristics of spasticity with different etiologies. ${ }^{27}$ The AS and MAS are simple to administer, are well tolerated, require no specialized equipment, but only address the velocity dependent aspect of spasticity across a single joint. The scale determines the amount of resistance felt during the passive displacement of a limb, but it does not account accurately for the dependence 
Table 1 Attributes of $\mathrm{SCl}$ spasticity outcome measures-procedural

\begin{tabular}{|c|c|c|c|c|c|}
\hline Attribute & AS/MAS & PSFS & SCATS & VAS & WPT \\
\hline Construct & Velocity-dependent stretch reflex. & $\begin{array}{l}\text { Patient self-report on } \\
\text { perceptions of spasticity } \\
\text { frequency and severity. }\end{array}$ & $\begin{array}{l}\text { Measures } 3 \text { distinct } \\
\text { components of lower } \\
\text { extremity spasticity: } \\
1 \text { Ankle clonus } \\
2 \text { Flexor reflex } \\
3 \text { Extensor reflex }\end{array}$ & $\begin{array}{l}\text { Patient self-report on the } \\
\text { impact of spasticity. }\end{array}$ & $\begin{array}{l}\text { Velocity-dependent stretch } \\
\text { reflex of the quadriceps. }\end{array}$ \\
\hline Procedure & $\begin{array}{l}\text { The resistance to passive movement through } \\
\text { the full range of motion about a single joint } \\
\text { for a relaxed target muscle is rated. }\end{array}$ & $\begin{array}{l}\text { The modified PSFS }{ }^{13} \text { queried } \\
\text { frequency and severity } \\
\text { separately. If no spasms } \\
\text { reported, severity ratings } \\
\text { not necessary. }\end{array}$ & $\begin{array}{l}\text { Rated supine observations of } \\
\text { clonus due to ankle } \\
\text { perturbation, flexor reflex due } \\
\text { to pinprick arch of foot and } \\
\text { extensor reflex due to leg } \\
\text { extension }\left(90^{\circ} / 110^{\circ} \text { knee/hip }\right. \\
\text { flexion) while contralateral } \\
\text { limb extended. }\end{array}$ & $\begin{array}{l}\text { Subjects instructed: 'rate your } \\
\text { spasticity of the time period } \\
\text { since you last rated.' }\end{array}$ & $\begin{array}{l}\text { With patient semireclined or } \\
\text { supine but supported to just } \\
\text { proximal to the knees, one } \\
\text { lower limb is extended and } \\
\text { let go to allow to swing } \\
\text { pendulously and freely. }\end{array}$ \\
\hline Scoring & $\begin{array}{l}\text { AS } \\
0=\text { no increase in tone } \\
1=\text { slight increase in tone giving a 'catch' when } \\
\text { the limb is moved in flexion or extension } \\
2=\text { more marked increase in tone but limb } \\
\text { easily flexed } \\
3=\text { considerable increase in tone-passive } \\
\text { movement difficult } \\
4=\text { limb rigid in flexion or extension } \\
\text { (adduction/adduction) } \\
M A S \\
0=\text { no increase in muscle tone } \\
1=\text { slight increase in muscle tone, manifested } \\
\text { by a catch and release or by minimum } \\
\text { resistance at the end of the range of motion } \\
\text { when the affected part(s) is moved in flexion or } \\
\text { extension } \\
1+=\text { slight increase in muscle tone, manifested } \\
\text { by a slight catch, followed by minimal } \\
\text { resistance throughout the remainder (less than } \\
\text { half) of the range of movement } \\
2=\text { more marked increase in muscle tone } \\
\text { through most of the range of movement, but } \\
\text { affected part(s) easily moved } \\
3=\text { considerable increase in muscle tone, } \\
\text { passive movement difficult } \\
4=\text { affected part(s) rigid in flexion or extension }\end{array}$ & $\begin{array}{l}\text { PSFS } \\
0=\text { no spasm. } \\
1=\text { mild spasms induced by } \\
\text { stimulation } \\
2=\text { infrequent full spasms } \\
\text { occurring }<1 / \mathrm{h} \\
3=\text { spasms occurring }>1 / \mathrm{h} \\
4=\text { spasms occurring }>10 / \mathrm{h} \\
\text { Modified PSFS: } 2 \text { part } \\
\text { Part } 1: \text { Spasms Frequency Scale } \\
0=\text { no spasms. } \\
1=\text { spasms induced only by } \\
\text { stimulation } \\
2=\text { infrequent spontaneous } \\
\text { spasms occurring }<1 / \mathrm{h} \\
3=\text { spontaneous spasms } \\
\text { occurring }>1 / \mathrm{h} \\
4=\text { spontaneous spasms } \\
\text { occurring }>10 / \mathrm{h} \\
\text { Part } 2: \text { Spasm Severity Scale } \\
1=\text { mild } \\
2=\text { moderate } \\
3=\text { severe }\end{array}$ & $\begin{array}{l}\text { SCATS clonus } \\
0=\text { no reaction. } \\
1=\text { mild, clonus }<3 \mathrm{~s} \\
2=\text { moderate; clonus } 3-10 \mathrm{~s} \\
3=\text { severe; clonus }>10 \mathrm{~s} \\
\text { SCATS flexor spasms } \\
0=\text { no reaction. } \\
1=\text { mild, }<10^{\circ} \text { of excursion } \\
\text { in flexion at knee/hip or } \\
\text { extension of great toe } \\
2=\text { moderate; } 10-30^{\circ} \text { of } \\
\text { excursion in flexion at } \\
\text { knee/hip } \\
3=\text { severe; } \geqslant 30^{\circ} \text { of excursion } \\
\text { in flexion at knee/hip } \\
\text { sCATS extensor spasms } \\
0=\text { no reaction. } \\
1=\text { mild, extensor contraction } \\
<3 \mathrm{~s} \\
2=\text { moderate; extensor } \\
\text { contraction } 3-10 \mathrm{~s} \\
3=\text { severe; extensor } \\
\text { contraction }>10 \mathrm{~s} / \text { joint }\end{array}$ & $\begin{array}{l}\text { 'No Spasticity' and 'Most } \\
\text { Imaginable Spasticity' } \\
\text { imprinted to the left and right, } \\
\text { respectively, of the } 100 \mathrm{~mm} \\
\text { VAS. }\end{array}$ & $\begin{array}{l}\text { Observations for: } \\
1 \text { number of oscillations } \\
2 \text { duration of oscillations } \\
3 \text { excursion of the backward } \\
\text { swing } \\
4 \text { relaxation index (first } \\
\text { swing excursion/difference } \\
\text { between starting and resting } \\
\text { angles) }\end{array}$ \\
\hline $\begin{array}{l}\text { Administration } \\
\text { Time }\end{array}$ & Minutes per muscle/joint & Minutes per muscle/joint & Minutes per muscle/joint & Minutes per muscle/joint & $\begin{array}{l}\sim 30+\text { minutes+data analysis } \\
\text { time }\end{array}$ \\
\hline
\end{tabular}

Abbreviations: AS, Ashworth Scale; IRR, inter-rater reliability; LE, lower extremity; MAS, Modified Ashworth Scale; PSFS, Penn Spasm Frequency Scale; SCATS, Spinal Cord Assessment Tool for Spastic reflexes; VAS, Visual Analogue Scale; WPT, Wartenberg Pendulum Test. 
Table 2 Attributes of SCI spasticity outcome measures-clinical utility

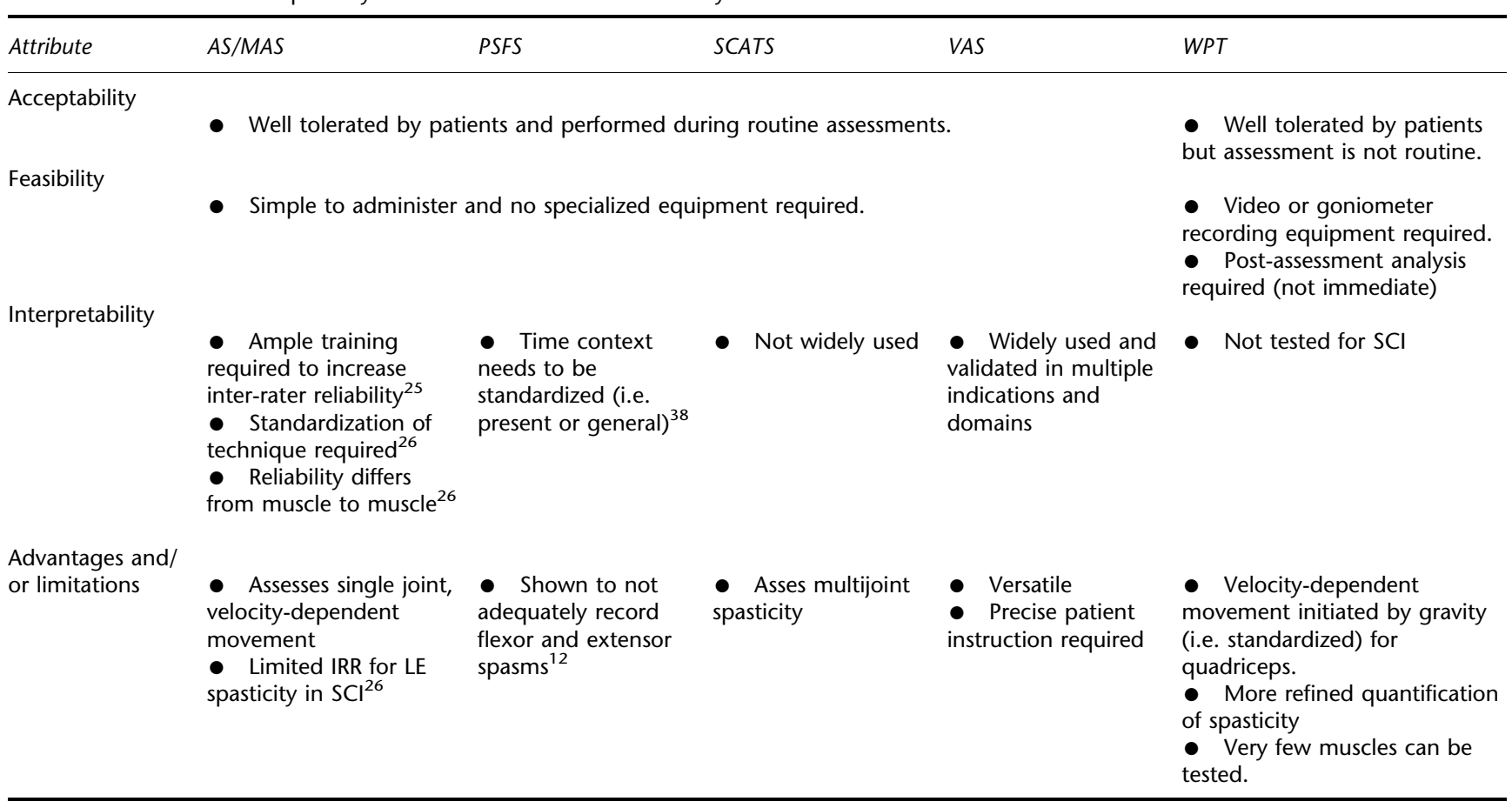

Abbreviations: AS, Ashworth Scale; IRR, inter-rater reliability; LE, lower extremity; MAS, Modified Ashworth Scale; PSFS, Penn Spasm Frequency Scale; SCATS, Spinal Cord Assessment Tool for Spastic reflexes; VAS, Visual Analogue Scale; WPT, Wartenberg Pendulum Test.

of the resistance to the velocity of the stretch, which can be highly variable from examiner to examiner. ${ }^{28}$ The psychometric properties for 10 AS and 4 MAS studies in SCI are summarized in Table 3 . The AS was found to have adequate inter-rater reliability ${ }^{29}$ for specific lower limb muscles, such as the adductors and flexors. However, inter-rater reliability was found to be poor for the plantar flexors. ${ }^{26}$

The AS correlates most strongly with the patellar tendon $\operatorname{tap}^{13}$ and less so with the VAS. ${ }^{30}$ Higher correlations were found between the MAS and VAS. ${ }^{23}$ Sherwood et al. ${ }^{31}$ obtained correlations of the AS and MAS with EMG and suggested that AS does not discriminate well at the low end of spasticity (AS score 0 vs 1 ) and Skold et al. ${ }^{32}$ reported increased correlation values when subjects with MAS grades of 0 were excluded. The AS also correlates well with SCATS, ${ }^{12}$ which was developed to measure, more comprehensively, the different types and severity of spastic reflexes in SCI.

Preliminary evidence of responsiveness has been demonstrated in various interventional studies as pre- and post-AS measurements reflecting declining spasticity progressed in the same direction as was also assessed by the PSFS. ${ }^{33-36}$

The AS and MAS were the spasticity outcome measures identified as those most commonly used $^{37}$ and psychometrically assessed in SCI. Overall, the AS and MAS have good clinical utility and increased standardization and training for test administration is needed to maximize reliability. Target muscle group and severity of spasticity should be considerations in the selection between AS and MAS. Validity for both AS and MAS has only been partially established and even less so for responsiveness.

\section{Penn Spasm Frequency Scale}

Penn et al. ${ }^{36}$ originally defined a five-point spasm frequency scale, which was later modified by Priebe et al., ${ }^{13}$ and referred to as the modified PSFS. The modified PSFS is a twocomponent self-report scale to augment clinical ratings of spasticity and provide a more comprehensive understanding of an individual's spasticity status. The first component is a five-point scale assessing the frequency with which spasms occur ranging from ' $0=$ no spasms' to ' $4=$ spontaneous spasms occurring more than 10 times per hour'. The second component is a three-point scale assessing the severity of spasms (SSS) ranging from ' $1=$ mild' to ' $3=$ severe'. The second component is not answered if the person indicates that they have no spasms in part 1 . This measure is simple and appropriate to the clinical setting and does not require specialized equipment to perform (Tables 1 and 2). A total of six studies of PSFS use in SCI were included in this review and their psychometric results are summarized in Table 3.

Reliability has not been established for PSFS in SCI. Validity for the PSFS has been partially established through correlations with other clinical tools, such as the $\mathrm{AS}^{13,33,35,36}$ and the SCATS. ${ }^{12}$ The PSFS correlated only moderately with routine clinical examination, suggesting that the elements of spasticity evaluated in the physical examination do not represent entirely what is important to persons with SCI spasticity. ${ }^{13}$ By utilizing a standard time specification for the self-report, Lechner et al. ${ }^{38}$ established that the 'present' spasm severity self-report (that is, rating of spasticity immediately upon Ashworth testing completion) correlated 
Table $3 \mathrm{SCl}$ articles reviewed for psychometric properties of AS and MAS and PSFS

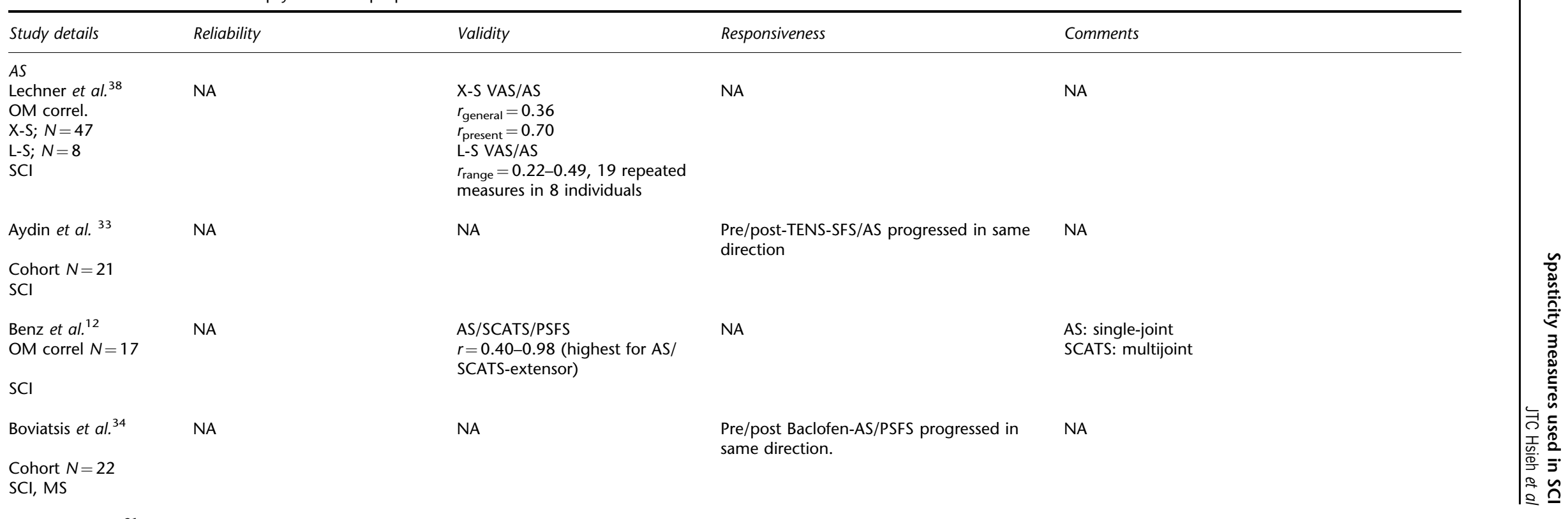

Sherwood et al. ${ }^{31}$

Cohort $N=97$

$\mathrm{SCl}$

Gianino et $a l^{35}$

Prosp. Cohort $N=25$

$\mathrm{SCl}, \mathrm{MS}$

Priebe et al. ${ }^{13}$

OM correl. $N=85$

$\mathrm{SCl}$

Lee et al. $^{43}$

Cohort $N=12$

$\mathrm{SCl}, \mathrm{MS}$

$t_{\text {inter }}=0.92$ (4 raters)

$\sim r=0.89(95 \% \mathrm{Cl})$

Penn et al. $^{36}$

Cohort $N=20$

NA

vs 2 and $3: P<0.001$

NS for AS 0 vs 1

NA

NA

$\mathrm{SCl}, \mathrm{MS}$

AS and MAS

Haas et al. $^{26}$

AS $\bar{\kappa}=0.41 ;$ Add/Flex $K=0.61$

PI.Flex $K=0.21$

IRR $N=30 \quad$ MAS $\bar{\kappa}=0.34 ;$ Add $/ F$ Flex
$K=0.62 ;$ Pl.Flex $\bar{\kappa}=0.20$
AS $P=0.00000014$

SFS $P=0.000017$

NA

NA

AS $P=0.0001$, SFS $P<0.0005$

Concomitant changes at $19.2 \mathrm{~m}$ follow-up
NA

Limited lower extremity i-r

Technique standardization, ample training and muscle selection $=\uparrow$ i-rr 


Study details Reliability Ralidity Responsiveness

MAS

Smith et al. ${ }^{44}$

MAS $\bar{\kappa}=0.14-035$

OM correl. $N=22$

V-MAS $\overline{I C C}=0.59-0.88$

$\mathrm{SCl}$

Skold ${ }^{23}$

NA

TR and OM correl.

$N=45$

$\mathrm{SCl}$

Skold et $a l^{32}$

OM correl. $N=15$

$\mathrm{SC}$

PSFS

Aydin et al. ${ }^{33}$

Cohort $N=21$

$\mathrm{SCl}$

Benz et al. ${ }^{12}$

OM correl. $N=17$

$\mathrm{SCl}$

Boviatsis et al. $^{34}$

Cohort $N=22$

$\mathrm{SCl}, \mathrm{MS}$

Gianino et al. ${ }^{35}$

Prosp. Cohort $N=25$

$\mathrm{SCl}, \mathrm{MS}$

Priebe et al. ${ }^{13}$

OM correl. $N=85$

$\mathrm{SCl}$

Penn et al. $^{36}$

Cohort $N=20$

NA
MAS/WPT $r=-0.69$

V-MAS/WPT $r=0.83$

VAS/MAS

$r=0.44-0.62$

$80 \%$ significant correlation

EMG/MAS, $P<0.05$

$25 \%$ when 0 removed $=$ end of

range effect

NA

PSFS/AS $r=0.40-0.51$

PSFS/SCATS $r=0.4-0.59^{*}$

$* P<0.05$

NA

$\mathrm{SFS} / \mathrm{IFS}=0.0407$

$\mathrm{SFS} / \mathrm{PSS}=0.312$

NA

NA

NA
Pre/post TENS-SFS/AS progressed in same direction.

Sig. correl. between PSFS and SCATS clonus suggests substantial role of clonus in perception of spasms

Pre/post Baclofen-AS/PSFS progressed in same direction

AS $P=0.00000014$

SFS $P=0.000017$

AS $P=0.0001$, SFS $P<.0005$ Concomitant

changes at 19.2 month follow-up
E-goniometer data collection

Sample not pre-selected for spasticity Abbreviations: AS, Ashworth Scale; CR, coefficient of repeatability; $\overline{I C C}$, mean intraclass correlation coefficient; IFS, Interference with Function Scale; $\bar{\kappa}$, Mean Kendall's tau; L-S, longitudinal study; MAS, Modified
Ashworth Scale; NA, not available; OM, outcome measure; OM correl., OM correlation; PI.Flex, plantar flexor; Prosp., prospective; PSFS, Penn Spasm Frequency Scale; PSS, Painful Spasm Scale; $r$, Spearman's correlation; SCATS, Spinal Cord Assessment Tool for Spastic reflexes; SEMG, surface electromyography; $t$, Kendall's tau; TENS, transcutaneous electrical nerve stimulation; TR, test-retest; X-S, cross-section.

${ }^{*} P<0.05$ 
modestly to AS, whereas the 'in general' spasm severity selfreport (that is, questionnaire rating of effects of daily life activities) correlated poorly to AS. In addition, the PSFS was found to correlate highest with the SCATS clonus measure as compared to the flexor and extensor spasm components of SCATS, suggesting that the role of clonus represents the client's highest perception of spasticity. ${ }^{12}$

Responsiveness over time has been exhibited in several studies employing the PSFS, within a test battery to assess spasticity-treatment interventions, ${ }^{33-35}$ which have been limited to demonstrations of significant differences but not with more robust psychometric testing methods described earlier.

The PSFS has good clinical utility and adds the patient's perspective, provided that standardization of the time of day and time frame (that is, present or general) for the report is established. Each of the psychometric properties requires further investigation with validity and responsiveness having been preliminarily examined.

\section{VAS to assess self-rated quantification of spasticity}

Another approach of patient self-reporting involves the VAS, which is a graphical scale that allows the patient to select the degree in which a construct of interest is graded from one extreme to the opposite. In general, VAS is a simple and quick method to establish a baseline and track progress after interventions. $^{23}$ In the present review, two studies each asked patients to rate their spasticity from 'no spasticity' to 'most imaginable spasticity' either within the previous hour $\left(\mathrm{VAS}_{\mathrm{H}}\right)^{23}$ or after completion of a specific test activity $\left(\right.$ VAS $\left._{\mathrm{SA}}\right) .{ }^{38}$

Convergent validity was demonstrated with significant correlations between $\mathrm{VAS}_{\mathrm{H}}$ and MAS. ${ }^{23}$ However, it must be noted that this validation cannot be applied generally to all self-reports recorded using VAS. For example, Lechner et al. ${ }^{38}$ found lower correlations between $\mathrm{VAS}_{\mathrm{SA}}$ and MAS, likely because patients scored their spasticity resulting from a specific activity rather than the general spasticity experienced over the previous hour. Furthermore, time of day for spasticity assessments seems to be more important in patients with cervical lesions due to more pronounced intrinsic diurnal spasticity fluctuations. ${ }^{23}$ As with the PSFS, the need to standardize the timing of measurements is important.

\section{Spinal cord Assessment Tool for Spastic Reflexes}

SCI reflex hyperexcitability is described frequently as including clonus and, flexor and extensor spasms. SCATS was developed by Benz et al. ${ }^{12}$ to measure SCI spasms and spastic hypertonia. SCATS is simple to administer as it is comprised of elements common to a standard neurological examination of the lower extremities. Despite simplicity, SCATS has yet to be adopted widely and only a single study has been included in this review. Initial validation of this new SCI spasticity outcome measure was accomplished via correlations with kinematic and electromyographic recordings. ${ }^{12}$ The SCATS extensor spasm score correlated highly with these measures in hip and knee flexors $(r=0.98$ and 0.88 , respectively) but less so for the ankle plantar flexors $(r=0.61)$. The SCATS flexor spasms and clonus scores correlated well with Ashworth scores but only the SCATS clonus score correlated significantly with PSFS $(r=0.59)$. Benz et al. ${ }^{12}$ noted that the SCATS provided additional information in comparison to the AS and MAS in assessing multijoint spasticity, whereas the AS and MAS are limited to spasticity assessment over a single joint. Further testing for reliability and responsiveness of SCATS is required.

\section{Wartenberg pendulum test}

From a simple and reliable clinical test of Parkinson lower limb hypertonia ${ }^{39}$ to quantification of similar changes secondary to upper motor neuron disorders, ${ }^{40}$ the pendulum test has been used for many years across indications to assess tone. The pendulum score is calculated during the gravity induced pendulum-like movement of the lower limb, as the ratio of joint angles measured by goniometers or computerized video motion analysis. Although the WPT is well tolerated by patients, it is not used widely in SCI spasticity assessment, likely due to the requirement for specialized equipment and post-assessment analysis. Validity and responsiveness have not been well established for WPT in SCI spasticity other than a single report. ${ }^{22}$ Although significant correlations between AS and the amplitude of first swing of the WPT were moderate at baseline, the correlation was higher during treatment when tizanidine was shown to decrease significantly muscle tone $(P<0.0001)$ from baseline. Significant treatment effects were found for tizanidine when the AS and the WPT were used as spasticity assessments, which provides preliminary evidence for responsiveness of WPT. ${ }^{22}$

The technical requirements for the WPT will likely limit widespread use. However, it is interesting to note that the WPT was used alongside the AS to assess spasticity in the only published multicentre RCT that led to the regulatory approval of an antispasmodic for SCI. ${ }^{22}$ However, if the use of WPT is planned for future trials, further psychometric validation in SCI is recommended.

\section{Discussion}

The primary purpose of this review was to summarize and interpret the available psychometric data for SCI spasticity outcome measurement tools in current use. We have identified six available tools referenced in the current SCI spasticity intervention literature ${ }^{37}$ having partial validation (for example AS, MAS, PSFS, VAS, SCATS and WPT). All six measurements have good clinical utility with the exception of the WPT, which requires additional equipment and data analysis. There is a need to provide further evidence of reliability, validity and responsiveness for all these measures in order that they can be used with confidence. In particular, investigations of responsiveness are universally lacking. The AS and MAS have the largest body of available psychometric 
data, but the identified limitations, especially with respect to validity and responsiveness for these measures in specific muscle groups, need to be addressed in further studies. SCATS has only been preliminarily assessed in one study, but the advantage of this clinically utilitarian tool warrants further investigation since this one tool will measure three distinct components of lower extremity spasticity.

Further data are also required for the inclusion of the PSFS in a spasticity assessment battery, especially in light of the importance for reflecting the patient's perspective on spasticity. Psychometric properties of PSFS have only been established in part, especially for responsiveness. Stronger evidence of responsiveness would require such techniques as receiver operator characteristic (ROC) curve analysis, the calculation of standardized effect sizes, standardized response means and analysis of change scores or relative efficiencies. Reporting time frame has been identified as an important consideration since immediate (that is, investigator-evoked spasticity) and general (that is, spasticity related to activities of daily living) spasticity do not correlate. $^{38}$

The simplicity of VAS as a scoring method of the patient's perception of spasticity is useful with respect to clinical utility, but it is important to note the significant differences in responses are highly dependent on the core question posed in each instance of VAS. As with the PSFS, VAS scoring of general spasticity experienced over the previous hour will likely differ from the VAS scoring of spasticity experienced after a specific activity. The flexibility of VAS is offset by the need to validate each unique spasticity-related question that the patient is asked.

Use of WPT is simple to administer, objective and quantifiable. $^{21}$ Since AS or MAS have limitations at the lower range of spasticity, ${ }^{4,26,31}$ it would seem plausible to suggest WPT as a substitute measure for potential investigation. However, the need for specialized equipment and post-test data analysis, along with the observation that WPT is not effective if the limb is too rigid to produce true oscillations, ${ }^{20}$ may prevent widespread use of this tool. As well, WPT has limited application in SCI spasticity, as it can only be examined in one muscle group (that is, quadriceps).

As noted previously, when selecting the optimal outcome measurement tools for spasticity assessment, one must consider the range of features of spasticity encompassed by the various definitions of spasticity. It has been suggested that no single outcome measure can capture the multidimensional nature of spasticity reflected over several definitions and represented by velocity dependency, frequency, severity, subclinical conditions, tonic spasticity (tone), phasic spasticity (hyperreflexia, clonus) and involuntary muscle spasms and so on. ${ }^{13,14}$ Focusing on one or two spasticity outcome measures may cause authors to over- or under-represent the magnitude of treatment effects. ${ }^{13}$ Priebe $^{14}$ has purported that spasticity is measured best by a battery of tests that recognize the many variables of spasticity including conditions, which are subthreshold for detection, as well as the patient's perspective and/or level of fatigue.
The degree to which a tool correlates with other tools that measure, theoretically, the same construct provides evidence for the convergent validity of that tool and several results have shown varying convergent validity depending on the specific tool and the circumstances under which it was administered (for example, body location, time). This suggests that different clinical scales are likely measuring different aspects within the spectrum of spasticity. ${ }^{13}$ The specific test battery employed by Priebe et al. ${ }^{13,14}$ included PSFS and AS, as well as Interference with Function, Painful Spasm and clonus. Priebe et al. also performed neurological tests such as deep tendon reflexes and plantar stimulation response. These measures cover, generally, the clinically important and distinct components of spasticity: tonic spasticity (tone), phasic spasticity (hyperreflexia, clonus) and involuntary muscle spasms.

A second consideration for selecting spasticity outcome measurement tools is they must assess adequately the range of functional activities that spasticity may impact. The ICF classification system provides a suitable framework, which should reflect the range of these functional activities. All of the measures included in the present review, and the vast majority of tools that have been employed in the literature reflect assessment of spasticity under the ICF category of body structure and function. One form of a patient selfreport measurement (that is, $\mathrm{VAS}_{\mathrm{SA}}$ ) was used to measure spasticity resulting from a specific activity (that is, potentially classified under ICF category of activity) and was only evaluated with respect to convergent validity in relation to MAS. No psychometric data were available for outcome measures targeted at measuring spasticity with respect to an individual's level of societal participation (that is, ICF category of participation). Body structure and function, activity, and participation are all important factors for predicting the success of spasticity interventions and it is apparent that current spasticity measurement tools are focused on the former but are lacking for the latter. In addition to the need to measure the different aspects of functional (body) spasticity, we suggest it is equally important to track the impact of spasticity on the other ICF categories (activity and participation), culminating in the impact on quality of life for the individual living with SCI.

Recent analysis of SCI patient perspective domains (that is, physical activity, emotional, economic, interpersonal, management and community access) underscores the lack of focus on what matters to the patient when assessing the success of spasticity-related interventions. ${ }^{41}$ The balance of controlling spasticity versus total suppression of spasticity is measured best from the individualized patient perspective. This gap identifies a significant need to develop a valid battery of outcome measures that also assess the impact of spasticity in limiting activity and participation. Priebe et al. ${ }^{13,14}$ have reported preliminary psychometric data on Interference with Function and Painful Spasm scales within their recommended test battery. The Interference with Function, along with PSFS and Painful Spasm scales, was found to correlate weakly with clinical assessments and modestly with each other. Further investigation is warranted for the Interference with Function and Painful Spasm scales, 
as measures of individual activities that are impacted by spasticity after SCI.

Without understanding the impact on activity and participation limitations, SCI spasticity interventions cannot reflect adequately a treatment benefit through clinical assessments at the body function level alone. Although there are certainly some SCI-specific measures that examine functional activity and participation limitations (for example, Craig Handicap Assessment and Recording Technique, CHART and Spinal Cord Independence Measure, SCIM), as well as other generic measures that have been validated partially for SCI, which address activity and participation (for example, FIM, SIP, SF-36), there are no measures that address the specific impact of spasticity in limiting activity or participation. One approach that may fill this void is the recent introduction of the SCI Spasticity Evaluation Tool (SCI-SET). ${ }^{42}$ At the time of paper submission, information about the SCI-SET was 'in press' and therefore was not included in the Results section as done for the other tools. The SCI-SET is a 35-item, 7-day recall self-report scale that has been designed to assess the impact of spasticity on various activities of daily living to issues of social participation. It incorporates a Likert-like scale with anchors of -3 (extremely problematic) to +3 (extremely helpful) in asking patients how spasticity symptoms have affected their lives. Initial developmental testing for the SCI-SET has demonstrated excellent internal consistency, test-retest reliability as well as face and convergent (construct) validity. Average time for completion was $6.8 \mathrm{~min}$, although more testing is required to more fully assess clinical utility, especially given the number of items, the need for post-test analysis and the 7-day recall aspect. The features of the SCI-SET also address the remaining considerations noted earlier and specifically on gaps that exist in the current armament of available tools (that is, assessing range of effects from negative to positive and use as a self-report tool that considers the patients perspective).

As researchers and clinicians, we should aim to assess the influence of new antispasmodic interventions by considering the multidimensional nature of spasticity, thereby making a test battery a suitable choice. Furthermore, an appropriate battery of reliable measures should consider clinical utility, be validated specifically for the construct of interest and include measurements of the impact on activity and participation as well as quality of life. For use in clinical trials as a primary outcome measure, much effort would be required to appropriately configure the tool content and scoring so as to reflect the multidimensional nature of spasticity and satisfy both clinical and regulatory requirements. Currently, the test battery recommended by Priebe et al. ${ }^{14}$ is a suitable starting point for most evaluations, but this should be augmented by additional patient-focused tools, such as SCI-SET.

\section{Acknowledgements}

We thank Dr John Steeves, Director of the International Collaboration on Repair Discovery (ICORD) and the John and Penny Ryan BC Leadership Chair, for the thorough review of the paper and ICORD personnel for organizational support. Funding for this project was provided by the Rick Hansen Man in Motion Research Foundation and the Ontario Neurotrauma Institute. Dr Miller receives salary support from the Canadian Institutes of Health Research.

\section{References}

1 Levi R, Hultling C, Seiger A. The stockholm spinal cord injury study: 2. Associations between clinical patient characteristics and post-acute medical problems. Paraplegia 1995; 33: 585-594.

2 Levi R, Hultling C, Nash MS, Seiger A. The Stockholm spinal cord injury study: 1. Medical problems in a regional SCI population. Paraplegia 1995; 33: 308-315.

3 Maynard FM, Karunas RS, Waring III WP. Epidemiology of spasticity following traumatic spinal cord injury. Arch Phys Med Rehabil 1990; 71: 566-569.

4 Skold C, Levi R, Seiger A. Spasticity after traumatic spinal cord injury: nature, severity, and location. Arch Phys Med Rehabil 1999; 80: $1548-1557$.

5 Johnson RL, Gerhart KA, McCray J, Menconi JC, Whiteneck GG. Secondary conditions following spinal cord injury in a population-based sample. Spinal Cord 1998; 36: 45-50.

6 Noreau L, Proulx P, Gagnon L, Drolet M, Laramee MT. Secondary impairments after spinal cord injury: a population-based study. Am J Phys Med Rehabil 2000; 79: 526-535.

7 Walter JS, Sacks J, Othman R, Rankin AZ, Nemchausky B, Chintam R et al. A database of self-reported secondary medical problems among VA spinal cord injury patients: its role in clinical care and management. J Rehabil Res Dev 2002; 39: 53-61.

8 Canadian Paraplegic Association. Workplace Participation National Survey of Canadians with SCI http://www.canparaplegic. org/en/Employment_and_Education_24/EMPLOYMENT_6/14.html 1996. 1-10-2007.

9 Lance JW. Symposium synopsis. In: Feldman RG, Young RR, Koella WP (eds). Spasticity: Disordered Motor Control. Year Book Medical Pubs: Chicago, 1980, 485-494.

10 Pandyan AD, Gregoric M, Barnes MP, Wood D, van Wijck F, Burridge $\mathrm{J}$ et al. Spasticity: clinical perceptions, neurological realities and meaningful measurement. Disabil Rehabil 2005; 27: 2-6.

11 Decq P. Pathophysiology of spasticity. Neurochirurgie 2003; 49 (2-3 Part 2): 163-184.

12 Benz EN, Hornby TG, Bode RK, Scheidt RA, Schmit BD. A physiologically based clinical measure for spastic reflexes in spinal cord injury. Arch Phys Med Rehabil 2005; 86: 52-59.

13 Priebe MM, Sherwood AM, Thornby JI, Kharas NF, Markowski J. Clinical assessment of spasticity in spinal cord injury: a multidimensional problem. Arch Phys Med Rehabil 1996; 77: 713-716.

14 Priebe MM. Assessment of spinal cord injury spasticity in clinical trials. Top Spinal Cord Inj Rehabil 2006; 11: 69-77.

15 World Health Organization. International Classification of Functioning, Disability and Health 2001. World Health Organization: Geneva.

16 Feinstein AR, Joseph BR, Wells CK. Scientific and clinical problems in indexes of functional disability. Ann Intern Med 1986; 105: 413-420.

17 Fitzpatrick JM, While AE, Roberts JD. Measuring clinical nurse performance: development of the king's nurse performance scale. Int J Nurs Stud 1997; 34: 222-230.

18 Andresen EM, Meyers AR. Health-related quality of life outcomes measures. Arch Phys Med Rehabil 2000; 81 (12 Suppl 2): S30-S45.

19 SCIRE Team. SCIRE: Spinal Cord Injury Rehabilitation Evidence 2006. http://www.icord.org/scire/.

20 Biering-Sorensen F, Nielsen JB, Klinge K. Spasticity-assessment: a review. Spinal Cord 2006; 44: 708-722.

21 Jamshidi M, Smith AW. Clinical measurement of spasticity using the pendulum test: comparison of electrogoniometric and videotape analyses. Arch Phys Med Rehabil 1996; 77: 1129-1132.

22 Nance PW, Bugaresti J, Shellenberger K, Sheremata W, MartinezArizala A. Efficacy and safety of tizanidine in the treatment of 
spasticity in patients with spinal cord injury. North American Tizanidine Study Group. Neurology 1994; 44 (11 Suppl 9): S44-S51.

23 Skold C. Spasticity in spinal cord injury: self- and clinically rated intrinsic fluctuations and intervention-induced changes. Arch Phys Med Rehabil 2000; 81: 144-149.

24 Ashworth B. Preliminary trial of carisoprodol in multiple sclerosis. Practitioner 1964; 192: 540-542.

25 Bohannon RW, Smith MB. Interrater reliability of a modified Ashworth scale of muscle spasticity. Phys Ther 1987; 67: 206-207.

26 Haas BM, Bergstrom E, Jamous A, Bennie A. The inter rater reliability of the original and of the modified Ashworth scale for the assessment of spasticity in patients with spinal cord injury. Spinal Cord 1996; 34: 560-564.

27 Noth J. Trends in the pathophysiology and pharmacotherapy of spasticity. J Neurol 1991; 238: 131-139.

28 Steeves JD, Lammertse D, Curt A, Fawcett JW, Tuszynski MH, Ditunno JF et al. Guidelines for the conduct of clinical trials for spinal cord injury (SCI) as developed by the ICCP panel: clinical trial outcome measures. Spinal Cord 2007; 45: 206-221.

29 Lee A, Patterson V. A double-blind study of L-threonine in patients with spinal spasticity. Acta Neurol Scand 1993; 88: 334-338.

30 Lechner HE, Feldhaus S, Gudmundsen L, Hegemann D, Michel D, Zach GA et al. The short-term effect of hippotherapy on spasticity in patients with spinal cord injury. Spinal Cord 2003; 41: 502-505.

31 Sherwood AM, Graves DE, Priebe MM. Altered motor control and spasticity after spinal cord injury: subjective and objective assessment. J Rehabil Res Dev 2000; 37: 41-52.

32 Skold C, Harms-Ringdahl K, Hultling C, Levi R, Seiger A. Simultaneous Ashworth measurements and electromyographic recordings in tetraplegic patients. Arch Phys Med Rehabil 1998; 79: 959-965.

33 Aydin G, Tomruk S, Keles I, Demir SO, Orkun S. Transcutaneous electrical nerve stimulation versus baclofen in spasticity: clinical and electrophysiologic comparison. Am J Phys Med Rehabil 2005; 84: 584-592.

34 Boviatsis EJ, Kouyialis AT, Korfias S, Sakas DE. Functional outcome of intrathecal baclofen administration for severe spasticity. Clin Neurol Neurosurg 2005; 107: 289-295.

35 Gianino JM, York MM, Paice JA, Shott S. Quality of life: effect of reduced spasticity from intrathecal baclofen. J Neurosci Nurs 1998; 30: $47-54$

36 Penn RD, Savoy SM, Corcos D, Latash M, Gottlieb G, Parke B et al. Intrathecal baclofen for severe spinal spasticity. $N$ Engl $J$ Med 1989; 320: 1517-1521.

37 Hsieh JTC, Wolfe DL, Connolly S, Townson AF, Curt A, Blackmer J et al. Spasticity after spinal cord injury: an evidence-based review of current interventions. Top Spinal Cord Inj Rehabil 2007; 13 (1 J6149): 81-97.

38 Lechner HE, Frotzler A, Eser P. Relationship between self- and clinically rated spasticity in spinal cord injury. Arch Phys Med Rehabil 2006; 87: 15-19.

39 Wartenberg R. Pendulousness of the legs as a diagnostic test. Neurology 1951; 1: 18-24.

40 Schwab RS. Muscle relaxants. Practitioner 1964; 192: 104-108.

41 Mahoney JS, Engebretson JC, Cook KF, Hart KA, RobinsonWhelen S, Sherwood AM. Spasticity experience domains in persons with spinal cord injury. Arch Phys Med Rehabil 2007; 88: 287-294.

42 Adams MM, Martin Ginnis KA, Hicks AL. Spinal cord injury spasticity evaluation tool (SCI-SET): development and evalutation. Arch Phys Med Rehabil 2007; 88: 1185-1192.

43 Lee KC, Carson L, Kannin E, Patterson V. The Ashworth scale: a reliable and reproducible method of measuring spasticity. J Neuro Rehab 1989; 3: 205-209.

44 Smith AW, Jamshidi M, Lo SK. Clinical measurement of muscle tone using a velocity-corrected modified Ashworth scale. Am J Phys Med Rehabil 2002; 81: 202-206. 